\title{
La pornografía a debate. Notas sobre sexualidad e identidad de género en los argumentos feministas
}

\author{
Ariel Martínez ${ }^{2}$
}

\begin{abstract}
SÍNTESIS
El presente artículo realiza un recorrido por el debate surgido entre las diferentes lineas del feminismo en torno a la pornografía. A partir de allí se analizan los principales núcleos teóricos que integran tal debate: el estatuto de la sexualidad desde diferentes enfoques conceptuales, los argumentos esencializantes de algunas feministas como recurso para combatir la pornografía, el problema de la pornografía en relación con la violencia contra las mujeres, las posibles conexiones y diferenciaciones entre las categorías de realidad y fantasía. Se enfatiza la complejidad de la trama que integra tales debates, sobre todo si se tiene en cuenta que la pornografía se integra en procesos sexistas más generales, conforma sólo un sintoma de un malestar cultural mucho más amplio y más profundo.
\end{abstract}

\begin{abstract}
This article makes an approach on the debate that emerged among the different lines of feminism around pornography. From there it begins an analysis of the main theoretical nucleus that integrates that debate: the statute of sexuality viewed from different conceptual approaches, the essential arguments of certain feminists as a resource to fight pornography, the problem of pornography in relation to violence against women, the possible connections and differentiations between the categories of reality and fantasy. It emphasizes the complexity of the theme that integrates such debates, above all if it is considered that pornography is integrated in more general sexist processes, it shapes just a symptom of a cultural discomfort much more wide and deep.
\end{abstract}

Palabras clave: Pornografía - sexualidad - feminismos - identidad.

Key words: Pornography - sexuality - feminisms - identity.

\section{Introducción}

Los debates suscitados en el campo del feminismo en torno a la pornografía son múltiples y polémicos. Es posible establecer, básicamente, dos grandes líneas: aquellas feministas para quienes 
"la pornografía es por esencia heterosexista, medio privilegiado de la violencia hecha a las mujeres y que, por esa razón, debe ser prohibida; y aquellas para quienes la pornografía, precisamente en virtud de su estatus de medio privilegiado, a través del cual cierta verdad del sexo es producida y difundida, constituye un desafío de subversión de las normas sexuales" (Dorlin, 2009, 113).

Aún así, la polifonía conformada por los diferentes feminismos requiere un análisis sutil de los argumentos esgrimidos en relación con cuál es, o debería ser, el lugar de la sexualidad en la vida personal, social y política (primer apartado). Por otra parte, el recurso a esencializar las identidades y las sexualidades -tanto femenina como masculina- parece ser útil, al menos en un primer tramo del trayecto, a la hora de establecer una plataforma sólida sobre la cual combatir la esensia masculina al interior de la pornografía. Sin embargo, "afirmaciones esencialistas o esencializantes (...) sirven también para, madurados los tiempos, reactualizar pactos patriarcales de exlusión" (Femenías, 2008, 16), por lo cual resulta necesario delimitar conceptualmente a las identidades de género de un modo más flexible, enfatizando a la vez las coordenadas políticas de tal categoría (segundo apartado). Tal perspectiva nos traslada hacia la reflexión sobre la falta de neutralidad a la hora de delimitar la categoría de pornografía. Un análisis que ubica lo pornográfico en diferentes contextos semánticos permite visibilizar el modo en que dicha categoría se entrama en las prácticas discursivas del sexo (tercer apartado). Un postulado que subyace a la mayoría de los posicionamientos en el debate, por antagónicos que sean, es que la pornografía representa la verdad del sexo. Dicha consideración permite enfatizar la distinción entre realidad y fantasía -verdadero arco de tensión que constituye el telón de fondo de la densidad conceptual de tales debates- para deslindar los riesgos que supone la superposición de tales categorías (cuarto apartado).

El debate es complejo y abigarrado. En ese sentido se intentan trazar algunas vías de acceso que, lejos de agotar el tema, se proponen delimitar el espesor de la trama. 


\section{Diferentes posturas denuncian la inestabilidad de las categorías ${ }^{2}$}

El análisis que Neil Thornton (1986) realiza sobre la temática establece algunas diferenciaciones que se ubican a la base de múltiples posturas. Desde una posición liberal, a criterio del autor, la sexualidad es esencialmente privada. Por un lado, es interpretada fundamentalmente como pre-social, biológicamente determinada y, por otra parte, se considera que su expresión en cada individuo es un elemento vital de la libertad humana. Al estar biológicamente constituida, la sexualidad permanece anclada en el mundo natural, consecuentemente alejada de los alcances del poder político. Por lo tanto, desde este punto de mira, "la sexualidad es un aspecto peculiarmente íntimo de la experiencia humana, un ingrediente vital y un medio para la expresión personal. En tanto una de las áreas más significativas de la esfera privada, la conducta sexual [constituye una sitio en donde] las normas personales morales son, por lo general, apropiadas y los principios públicos que tienen que ver con el control o la coacción no tienen ningún lugar" (Thornton, 1986, 27). Por otra parte, la pornografía es una representación explícita de la actividad sexual, en consecuencia privada, y su empleo forma parte de esta actividad sexual igualmente privada. Desde aquí, la pornografía no genera mayores inconvenientes, a no ser que desborde lo privado e invada la esfera pública causando daño físico u ofensas a otras personas.

Desde una perspectiva moral conservadora, tal como la sistematiza Thornton, la actividad sexual es considerada como un instinto natural $\mathrm{u}$ otorgado por Dios. Constituye una fuerza rebelde y potencialmente perturbadora que debe ser limitada por el dominio sagrado de la familia patriarcal nuclear. "Mientras se encuentre dentro de este reino restringido, el sexo es seguro, personal y privado; pero fuera de este reino se hace inmoral, motivo por el cual es legítimo subsumirlo a la rigurosa regulación de lo público" (Thornton, 1986, 27). La pornografía, desde esta óptica, representa el sexo explícito, ilícito y como tal constituye un daño serio ya que amenaza a la familia nuclear y debilita la estructura moral de la sociedad. Su supresión política es, en consecuencia, un deber público. 
Dentro del movimiento feminista, según Elisabeth Badinter (2003), el análisis político más influyente en relación con la pornografía es el articulado por las feministas radicales. Para ellas, la sexualidad es, principalmente, una construcción sociopolítica. Es decir que la sexualidad adviene en una preocupación política nodal dado que constituye una muestra clara de los modos en que los varones ejercen poder sobre las mujeres sin máscaras. Esta perspectiva, que disuelve parcialmente la distinción liberal entre lo privado y lo público, identifica a la sexualidad como el principal ámbito social del poder masculino. Si bien la dominación masculina se aplica a todas las instituciones sociales, tiene sus raíces en el control de los hombres sobre la sexualidad de la mujer (Dworkin, 1981). El sexo, en particular el heterosexual, se considera como la base principal de la opresión de la mujer. Según esta opinión, la conciencia masculina define a las mujeres como seres sexuales, en el sentido más natural del término. Además, se ha conceptualizado la sexualidad de las mujeres en relación con la capacidad de despertar el deseo sexual en los hombres. Dicho de otro modo, lo que se supone que es sexual para una mujer es lo que los varones necesitan para la excitación. "Las feministas radicales consideran que en las prácticas (hetero) sexuales, en una sociedad dominada por los varones, predomina la posición dominante-subordinado, ideología de la objetivación sexual y de erotización de la opresión de la mujer" (Collins, 1990, 10). En este sentido, la libertad sexual femenina exige relaciones igualitarias en el que la sexualidad y la emotividad global se entrelazan. Por ello, las feministas radicales rechazan la objetivación sexual.

En relación con la pornografía, uno de los primeros análisis feministas radicales en relación con el tema, tal como señala Barbara Collins (1990), argumenta que las imágenes pornográficas reducen a las mujeres a objetos. El resultado, afirma, es socavar el eros femenino, caracterizado por la integridad física y emocional, la autonomía y la igualdad. Según las feministas radicales, entonces, las imágenes pornográficas influyen directamente en la violencia contra las mujeres. A criterio de Collins, las feministas radicales aceptan de manera acrítica la reiterada evidencia anecdótica que encuentran en relación con el papel de la pornografía en la victimización de las mujeres. En esta línea de pensamiento, las feministas radicales han propuesto y apoyado criterios jurídicos para la lucha contra la pornografía, dado que las imágenes 
que la integran constituyen el corazón mismo del daño contra las mujeres. Claramente, este enfoque define la pornografía como una forma de sexismo. Debido a que la pornografía es interpretada como propaganda de la misoginia sexual, cualquier defensa de la misma es vista como defensa del derecho de los hombres a utilizar el sexo para instrumentar el dominio sobre las mujeres. La pornografía, entonces, se encuentra completamente politizada, y es interpretada como una de las principales manifestaciones de la dominación patriarcal.

Un rastreo más detenido de las diferentes posturas en relación con la sexualidad y la pornografía al interior del feminismo, le permite a Collins distinguir dos puntos de vista claramente diferenciales más allá del feminismo radical. Estos son: el feminismo liberal y el feminismo socialista.

El feminismo liberal sostiene que

la sexualidad es resultado de los ideales políticos imperantes (...), los seres humanos son esencialmente agentes racionales. Los supuestos relativos a la autonomía y los ideales políticos definen la buena sociedad y permiten a cada individuo la máxima libertad de interferencias provenientes de otros individuos. (...) Sostienen que la sociedad ha estado históricamente caracterizada por la represión de la sexualidad, especialmente de las mujeres y de las minorías sexuales. Por lo tanto, entienden que la liberación sexual es un componente crucial de la liberación de las mujeres (...) Argumentan que la posición en contra de la pornografía asumida por las feministas radicales alimenta las actitudes y las creencias tradicionales estereotipadas sobre los modos apropiados de expresión sexual femenina (Collins, 1990, 12-13).

De este modo, hace hincapié en que, históricamente, las leyes que regulan la sexualidad han incorporado y reforzado una perspectiva que supone que las mujeres necesitan protección, y que la sexualidad masculina es agresiva y debe ser restringida por la ley.

Si bien gran parte de las "imágenes pornográficas pueden resultar ofensivas, las feministas liberales sugieren que también permiten una visión ampliada de las posibles realidades" (Collins, 1990, 14). Estos mensajes incluyen la idea de que la sexualidad no tiene por qué estar vinculada a la reproducción, a los hombres o a la domesticidad, y que el sexo puede ser sólo por 
placer. Desde este punto de vista, las imágenes pornográficas también pueden proporcionar a las minorías sexuales un medio de autoexpresión y autoafirmación que raramente esta disponible en los principales medios de comunicación. El argumento feminista liberal parece descansar, en última instancia, sobre la protección de la libre elección. Sostienen que censurar o limitar la pornografía conduce a una mayor represión por parte de los gobiernos conservadores y los tribunales dominados por los varones. Proponen, entonces, la educación sexual y la producción de imágenes pornográficas alternativas definidas por las propias mujeres como medio para recobrar la sexualidad de las mujeres.

Desde otra pespectiva, las feministas socialistas han reflexionado sobre las formas en que la naturaleza de las mujeres está construida socialmente. Afirman que aquello que define la especificidad de la identidad de género, los deseos y las necesidades sexuales, masculinas y femeninas, se forman a través del significado sexual asignado a la anatomía de los cuerpos en el marco de una "cultura heterosexista, y por una división sexual del trabajo que ha sido universal en la historia humana (...) Para las feministas socialistas, existe un problema común con las otras dos posiciones: tanto las feministas radicales como las feministas liberales basan sus perspectivas sobre un estado imaginado de naturaleza sexual" (Collins, 1990, 15). Las feministas socialistas señalan que las críticas de las feministas radicales a la pornografía refuerzan la idea de que existe un elemento esencial de la sexualidad femenina que podría manifestarse si las mujeres fueran liberadas del control de los hombres. Del mismo modo, las feministas socialistas afriman que los argumentos que sostienen la libertad de los individuos para realizar elecciones sexuales individuales dan por sentado que las sexualidades pueden tener existencia al margen de su contexto.

Las feministas socialistas sostienen que las prácticas sexuales, y el deseo en sí, deben considerarse como situados en un contexto social y material, las experiencias e imágenes sólo pueden ser interpretadas de acuerdo con los códigos imperantes de significado. Por ende, la sexualidad femenina en una cultura patriarcal capitalista da lugar tanto al erotismo como a la victimización. Las imágenes sexuales de varones y de mujeres son construidas por relaciones y prácticas sociales - patriarcales y capitalistas. Las feministas socialistas analizan los modos en que las mujeres 
son vistas, incluso por ellas mismas, no como personas con una multitud de deseos, intereses y capacidades, sino más bien como seres fragmentados que dan lugar al fetichismo sexual y a la objetivación de ciertas partes de sus cuerpos. En última instancia, las feministas socialistas tratan de comprender el modo en que la sexualidad ha sido construida en el patriarcado para producir las formas de dominación-sumisión.

La pornografía, desde este punto de mira, es sólo una parte del despliegue ideológico. Supone que la representación y los actos sexuales están incrustados en múltiples discursos políticos, religiosos, económicos, y sociales. Es claro que las feministas socialistas no interpretan "la pornografía como aquello que conduce a la violación, tampoco como una forma de resistencia cultural, sino como parte de la representación ideológica de género" (Collins, 1990, 17). Esas imágenes sexistas, tal como sostienen, se encuentran no sólo en la pornografía, sino en diversas manifestaciones que invaden la esfera de la sociedad. Es decir que, la pornografía, en sí, es un producto histórico variable en relación con los diferentes momentos y lugares. Tal es así que la pornografía no constituye un modo de imponer imágenes falsas sobre las mujeres, sino una forma de representación de un discurso masculino dominante. En este sentido, afirman que la pornografía desvía a las feministas de críticas más globales. Al igual que las feministas radicales, las feministas socialistas atacan el contenido de la pornografía como sexista, y censuran la explotación de las mujeres, sin embargo, debido a que las feministas socialistas insisten que tanto la sexualidad como la pornografía son construidas por, e integradas en, la cultura. También contemplan en sus análisis que el contexto material dentro del cual la sexualidad se desarrolla se modifica, por lo tanto también la pornografía está sujeta a transformaciones.

No se debería perder de vista, tal como señala Collins, que el objetivo nodal de las feministas socialistas es el cambio social, y, a criterio de ellas, el activismo antipornografía, en última instancia, no se dirige hacia aquel fin. Al considerar que los cambios básicos de las identidades y los comportamientos sexuales no son el resultado directo de suprimir imágenes, no se focalizan en cuan ofensiva pueda ser la pornografía, ya que no encuentran allí la causa principal de la opresión de las mujeres, sino en las estructuras sociales y económicas que crean su dependencia 
y conducen a su impotencia y objectalización en una cultura misógina. En esta línea, se constituye la critica a la preocupación excesiva en la literatura feminista respecto al papel de las representaciones sexuales como causa de la opresión de las mujeres, ya que pierde de vista la familia, la religión, la educación, las prácticas de crianza, los medios de comunicación, el Estado, la psiquiatría, la discriminación en el trabajo, y la paga desigual, entre otros elementos de un gran espectro.

Finalmente, Barbara Collins concluye que cada uno de los modelos sobre la pornografía conduce a una postura política en cuanto a la sexualidad, y a la fabricación y distribución de la pornografía. Mientras que para los liberales las estructuras de poder político son extrínsecas a la vida sexual (privada), para las feministas radicales, por ejemplo, el patriarcado es tomado como una dimensión política inseparable de los aspectos considerados como más individuales e íntimos (Millet, 1995). A partir de allí, la pornografía es identificada con el ejercicio del poder político que afecta a todas las relaciones humanas, incluso penetra hasta lo más privado. Como señala Denise Thompson (1992), la oposición entre lo político y lo erótico es insostenible en términos feministas. Desde el inicio, el feminismo ha señalado la naturaleza política de lo erótico, en donde la sexualidad masculina constituye uno de los pilares centrales en la organización del patriarcado.

Tal como señala Neil Thornton, la violación, los abusos, el acoso sexual y la pornografía se manifiestan en un flujo de prácticas interconectadas que giran en torno a las formas en que los seres humanos experimentan, expresan y viven la sexualidad. En este sentido, desde los diversos posicionamientos en el abordaje de la pornografía, tal como hemos visto, se desprenden consideraciones específicas en relación a la naturaleza de la sexualidad. El significado de tal término sufre modificaciones con el transcurso del tiempo, de acuerdo a las diferencias entre cada sociedad, y al interior de ellas según los diferentes sectores sociales. Incluso algunas sociedades carecen de tal categoría.

Tal como afirmamos al inicio, las definiciones de pornografía varían según lo que se asume como la naturaleza de la sexualidad, el lugar que tiene en la vida personal y política, y de acuerdo a las formas en que esta se articula con las prácticas de producción y de consumo (Attwood, 2002).

En esta línea, podríamos afirmar que nada es intrínsecamente 
pornográfico (Reed, 1994). Aún así, aunque el intento por reconstruir la pregunta respecto a los significados posibles de la pornografía es necesaria e inevitable para un abordaje del tema en su mayor complejidad posible, nada nos impide señalar el carácter prescriptivo de tales definiciones. La potencialidad de la pornografía para el daño parece construirse en su definición misma. Por tanto, cada postura selecciona un rasgo que considera central y que resulta potencial o efectivamente dañino $u$ ofensivo.

Neil Thornton demuestra lo problemático que resulta el abordaje del tema, los dilemas que se encuentran en la base de los debates transforman cada posible respuesta en un laberinto que nos devuelve al punto de partida. Por un lado, es posible analizar, junto al autor, que llevar el eslogan lo personal es político hasta sus últimas consecuencias implicaría disolver los límites entre lo público y lo privado. Parece más correcto comprender que si bien hay una línea entre lo público y lo privado, el modo liberal de trazarla es insostenible. A criterio del autor, la dicotomía liberal entre lo privado y lo público es una forma de mistificación ideológica que establece una compartimentalización demasiado artificial entre dos reinos estrechamente interconectados. Ahora bien, en la interpretación que sitúa a la sexualidad como privada, los liberales han dejado inmune de la regulación estatal a ciertas manifestaciones patriarcales que son sumamente opresivas para las mujeres, por ejemplo la violación dentro del matrimonio. En relación a la pornografía, por un lado podría pensarse que los derechos basados en la libertad de expresión y en la intimidad protegen a los autores de productos pornográficos y a los consumidores masculinos de pornografía al mismo tiempo que dañan los intereses de las mujeres. Esto es un claro ejemplo del modo en que "un soporte político ayuda a sostener el patriarcado" (Thornton, 1986, 34). Por otra parte, la prohibición legal de la pornografía reclamada por algunas feministas radicales amenaza la libertad de expresión y la libertad personal, incluyendo a las propias feministas.

\section{Identidades y sexualidades esencializadas}

Andrea Dworkin (1981), por ejemplo, entiende la agresión masculina como una expresión directa de la biología. Este reparto sitúa la sexualidad femenina, por contraste, como no agresiva, 
sensible y basada en lazos de solidaridad y mutuo apoyo. La representación de una sexualidad agresiva como exclusivamente masculina se encuentra a la base de una pornografía que celebra y refuerza el camino con el que los hombres dominan a las mujeres en el sexo heterosexual. En este contexto, la sexualidad masculina es siempre agresiva, egoísta y más o menos violenta. De este modo se insiste en una esencia masculina ontológicamente no suceptible de transformación por hallarse incardinada en una naturaleza ahistórica y atemporalmente entendida (Osborne, 1993).

Podemos pensar que a los planteos de las feministas radicales subyace la búsqueda de una correcta forma de sexualidad, alejada de la esencia masculina violenta y dominante. En efecto, establecen un notable contraste entre una sexualidad ideal y una sexualidad contaminada, o torcida. La feminista lesbiana Denise Thompson (1992), como estrategia política, señala que sólo mediante el amor entre mujeres es posible crear una nueva conciencia, cuestión que, a criterio de Thompson, está en el corazón mismo de la liberación de las mujeres. Si la sexualidad masculina se ubica en el anverso de la sexualidad de las mujeres -ya que está genitalmente fijada e impulsada hacia la explotación sexual, la dominación, incluso la violencia-, entonces se trata de intentar suprimir las características negativas de la masculinidad e incorporar elementos positivos de las mujeres en la sexualidad.

La sexualidad femenina como erótica, difusa, suave, fundada en el cuidado y en el respeto de la pareja, es decir valorada positivamente, parece teñir a tal sexualidad esecializada con un tinte sumiso. En esta línea de pensamiento, la sexualidad humana admitiría una distinción esencial entre mujeres y varones. Entonces, asumir la esencia agresiva del varón conlleva asumir la esencia masoquista de la mujer, lo cual explicaría y justificaría, al menos en una primera aproximación, la participación de las mujeres en la dominación sexual. Como plantea Jessica Benjamin (1996), algunas feministas radicales han tomado como recurso, para evitar afirmar una naturaleza femenina sumisa y violada, explicar su situación por medio de la coerción, ya que "si los hombres son inevitablemente lo que son, ¿cómo podrían las mujeres no ser lo que son?" (Benjamin, 1997, 198). La rigidez de la complementariedad entre las identidades esencializadas (una activa y la otra pasiva, una sádica y la otra masoquista) nos conduce al inevitable desenlace de la objetivación, para ambos polos identitarios. 
Tal como subraya María Luisa Femenías (2008), es posible entender las identidades como esenciales o, por el contrario, como complejas construcciones políticas. Constituye un ejemplo de la primera opción los desarrollos de Robert Jensen (1996). El autor amplía la crítica feminista radical contra la pornografía. Argumenta que el paradigma dominante de masculinidad permite actos de degradación en las películas pornográficas. Estos actos son las ventanas metafóricas que permiten ver claramente las formas en que nuestra sociedad considera a las mujeres (Jensen, 2007). Para Jensen, el único modo de terminar con la pornografía y la jerarquía patriarcal es abandonar totalmente el concepto de masculinidad, dado que carga en sí la estructura patriarcal de dominación. Los actos sexuales representados sobre la pantalla constituyen un símbolo, a modo de monumento recordatorio, del modo en que los hombres ganan placer en la degradación de las mujeres. Su acercamiento teórico a la masculinidad afirma que los hombres son naturalmente competitivos, agresivos y buscan el control, la conquista, y la dominación. Sus reflexiones están plagadas de argumentos que simplifican la cuestión al extremo y nos guían hacia una comprensión esencializada de las identidades.

$\mathrm{Si}$, por el contrario, optamos por la segunda vía, "reconocemos la identidad en términos de construcción constante, con estabilidad homeostática y pluridimensional, donde el proceso de identificaciones múltiples implica la autodefinición, tanto conciente como inconsciente, de lo que es ser un sujeto mujer" (Femenías, 2008, 22) o un sujeto varón. Desde esta perspectiva, Benjamin, a partir de postulados psicoanalíticos, concluye la simpleza de, por ejemplo, el análisis de Catherine MacKinnon, quien asegura que el dominio masculino está sexualizado como placer y anclado en la identidad de género masculina. En este sentido, es imposible separar de la sexualidad el componente de violencia. Por lo tanto, la creencia en que la violencia es sexo auspicia de postulado subyacente a una demonización esencializadora excesiva (Ciclitira, 2004). Con estas afirmaciones se clausura la posibilidad de ir más lejos, como por ejemplo interrogarnos, junto a Benjamin, ¿qué es exactamente lo que hace que la sexualidad transmita relaciones de poder, violencia y destrucción?

Según las feministas radicales más resistentes, la pornografía nada tiene que ver con el amor o con relaciones sexuales de 
mutualidad, su objeto es "la dominación, la violencia y la conquista" (Steinem, Cit. En Thornton, 1986, 29). Para Andrea Dworkin "la palabra pornografía no tiene ningún otro significado que dominación y violencia contra las mujeres" (Dworkin, 1981, 200). Como observa Denise Thompson (1991), tempranamente el feminismo radical fue muy crítico de la heterosexualidad. Las filosas afirmaciones, a finales de la década del 70, en los Estados Unidos, de algunos grupos de feministas lesbianas lanzaron, lo demuestran:

Cualquier mujer que forma parte de una pareja heterosexual contribuye a sostener la supremacía masculina reforzando sus cimientos (...) Cada acto de penetración es para la mujer una invasión que socava su confianza y debilita su fuerza. Para un hombre es un acto de poder y dominio que lo hace más fuerte, no sólo por encima de una mujer sino de todas las mujeres. De modo que cada mujer que practica la penetración refuerza al opresor y al poder de los hombres (Leeds Revolutionary Feminist Group, Cit. En Thompson, 1991, 392).

De este modo, la heterosexualidad es el paradigma de la violencia. El sexo heterosexual es violencia, afirmación que se construye sobre la base de una identidad masculina altamente esencializada.

Carolyn Dinshaw (2008) advierte los riesgos de abordar la sexualidad de manera abstracta, por ello aboga a favor de concebir la sexualidad en tanto una actividad que compromete a personas reales. En esta línea, Jessica Benjamin, contribuye a dejar de pensar en modelos teóricos que sostienen características de la vida erótica anudadas a identidades de género esencializadas. Es posible comenzar a pensar la identidad en su carácter intersubjetivo y relacional, renunciando a construcciones de un rasgo único y fijo (Femenías, 2008).

Actualmente, en la múltiple literatura sobre el tema, es posible hallar un relativo consenso en relación a comprender la configuración de la identidad personal como un fenómeno complejo en el que intervienen diversos factores, éstos van desde la dimensión intrasubjetiva hasta la adquisición de diversas capacidades suscitadas en el proceso de socialización y educación -en sentido amplio (Mayobre Rodríguez, 2006). Robert Stoller (1968) entiende por identidad de género al sentimiento de pertenencia al conjunto 
varón o mujer, que se establece precozmente, antes del conocimiento que cada niño/a tiene de la diferencia sexual anatómica y el papel de los genitales en la reproducción. Dicho de otro modo, el sentimiento que el propio niño/a tiene de ser varón o mujer (Lamas, 1986). En palabras de Emilce Dio Bleichmar, el "conjunto de prescripciones y prohibiciones para el ejercicio de una conducta, así como un sentimiento del ser que se reconoce (femenino o masculino) por desempeñar las actividades y conductas propias de su condición, y es reconocido por los otros en tanto se ajusta a ese desempeño esperado" (Dio Bleichmar, 1992, 135).

Si bien todo parece indicar que el proceso de la construcción de la identidad generizada no se realiza de la misma manera en las niñas que en los niños, hay quienes no acuerdan con estas consideraciones. Por un lado, los géneros -vale decir, las normas diferenciadas elaboradas por cada sociedad para cada sexo-, no tienen la misma consideración social, existiendo una clara jerarquía entre ellas. Desde esta perspectiva no faltan quienes aseguran que esa asimetría se internaliza en el proceso de adquisición de la identidad de género, que se inicia desde el nacimiento con una socialización diferencial, mediante la que se logra que los individuos adapten su comportamiento y su identidad a los modelos y a las expectativas creadas por la sociedad para los sujetos masculinos o femeninos.

Desde un punto de mira que considera la alianza entre feminismo y postmodernismo, Nancy Fraser y Linda Nicholson (1992) se apartan de todo tipo de explicación que, a modo de meta-narración, consolida explicaciones globales, esencialistas y monocausales. En esta línea, rechazan en bloque cualquier tipo de explicación del ordenamiento actual de los géneros basada en la socialización de los roles de género, del mismo modo también desechan explicaciones que giren en torno a la identidad genérica. A criterio de las autoras, dicha categoría supone, al menos tres premisas ineludibles:

[a] Todas las personas tienen un profundo sentido del yo que se constituye en la primera infancia a través de las interacciones con el padre o la madre y que permanece relativamente constante de ahí en más. [b] Ese yo profundo difiere significativamente en varones y mujeres pero es relativamente similar entre mujeres y entre varones. [y c] Ese yo profundo tiñe todo lo que una persona hace (Fraser y Nicholson, 1992, 20-21). 
Es claro que el establecimiento de estas premisas impulsa a las autoras a rechazar explicaciones que integren en sus marcos conceptuales la categoría de identidad genérica. Por el contrario, autoras como Jessica Benjamin $(1996,1997)$ y las últimas producciones de Nancy Chodorow (2003) se han esforzado por buscar nuevas perspectivas. La búsqueda de múltiples aristas que les permitan el ingreso a tal categoría sorteando el riesgo de quedar impregnadas del esencialismo y del a-historicismo constituye un objetivo que sobrevuela sus conceptualizaciones.

Jessica Benjamin (1997) advierte que el concepto de identidad genérica trae consigo el riesgo de concebir la misma como un todo coherente, homogéneo y uniforme. Propone, entonces, una concepción del desarrollo temprano de las identificaciones genéricas en la que la categoría misma de identificación, en tanto proceso intrapsíquico, es central. Sustituye la categoría de identidad genérica nuclear, así conceptualizada por Robert Stoller, por la de identificación genérica nominal, denominación con la que refiere a la representación primordial que se lleva a cabo durante el primer año de vida, producto de interacciones generalizadas (Bejamin, 1997). A criterio de la autora, la categoría de identificación genérica nominal como proceso resulta más apropiada que la categoría de identidad genérica nuclear en tanto producto. La perspectiva de proceso hace de la identidad un tanto más volátil, donde circulan sucesivas identificaciones, una multiplicidad en sí misma, un juego continuo de aspectos diversos, fracturados, del sí mismo que plasman la idea de que existen diferencias dentro (Braidotti, 1994). En la línea de la perspectiva que se pretende transmitir, resultan articulables, al menos en parte, algunos conceptos de Nancy Chodorow, quien propone pensar el modo en que se recrean las categorías dicotómicas de género socialmente ofertadas desde la singularidad de cada uno de los sujetos. Es así que la identidad de género conjuga producciones de significación provenientes de la cultura con aspectos provenientes de la historia libidinal e identificatoria (Aulagnier, 2004) de cada quien. Recreación constante a lo largo de toda la vida.

La concepción de identificaciones múltiples alienta el rechazo de concebir a la identidad en términos de coherencia y falta de ambigüedades. Si bien el sentido de pertenencia a uno de los núcleos identitarios organiza toda la experiencia genérica, la identidad plena como emanada de un núcleo delimitado y coherente, y 
que además clausura la condición de género replegándola sobre sí misma y clasificándola en polaridades rígidas, no es más que una de las tantas ficciones que obedece a la lógica del pensamiento moderno (Butler, 1990). El yo, y su identidad, muestran su faz inestable, al estar sometido, aunque sea en parte, a la posibilidad de cambio.

En este contexto, varias autoras han cuestionado el binarismo propio de la lógica moderna, desde donde realiza sus aportes el psicoanálisis en lo referente a la identidad sexual. Shulamit Reinharz (1992) rechaza la idea de "posiciones fijas", prefiere pensar que nos movemos alrededor de un "continuum", Alison Young (1992) propone la analogía con los colores de un espectro, Mary Gergen (1992) y Jessica Benjamín (1996) se posicionan a favor de una postura superadora que intenta tender un puente entre polaridades, establecer una conexión no excluyente entre opuestos, en este sentido Denise Thompson (1992) relativiza la existencia de identidades rígidas, discretas y dicotómicamente organizadas.

\section{El problema de la pornografía}

Helen Longino (Cit. en Thornton, 1986) afirma que la pornografía aprueba la degradación del comportamiento sexual de la mujer, el cual queda en evidencia principalmente a través de características contextuales. Aunque las mujeres que participan en los materiales pornográficos son representadas con la sensación de placer sexual, por lo general, de acuerdo a la autora, aparecen disfrutando de su propia humillación y, en cada situación, se insinúa que su placer sexual es subsidiario o auxiliar al placer sexual de los varones. En ese contexto, la pornografía maltrata a las mujeres al reducirlas, en la representación de los materiales, a objetos sexuales a ser explotados y manipulados para satisfascer el placer carnal de los hombres. La mujer es utilizada, entonces, para servir al deseo sexual de un hombre sin tener en cuenta su propia voluntad.

Todo parecería indicar que la naturaleza misma de la pornografía requiere que las mujeres sean tratadas como objetos sexuales. En esta línea de pensamiento es posible afirmar que en la pornografía se encuentra la aprobación de una conducta sexual 
que resulta humillante y degradante para las mujeres, así como la infracción más patente a su dignidad. Sin embargo, la existencia de otras pornografías específicas para otro tipo de clientes plantea un problema para el concepto de pornografía que manejan las feministas radicales, quienes parecen hacer referencia, principalmente, a los materiales, visuales o escritos, con contenido heterosexual y sexualmente explícitos, diseñados para excitar sexualmente a los espectadores o lectores masculinos (Thornton, 1986). Aunque Helen Longino (Cit. en Thornton, 1986) afirma que aún en los materiales en donde los varones no forman parte de la acción siempre es sencillo deducir, a partir de rasgos contextuales, la degradación de las mujeres, la existencia de otras pornografías específicas, como la de gays, no deja absolutamente en claro que la pornografía sea irremediablemente sexista.

Por otra parte, ¿todas las representaciones sexistas presentes en la pornografía desarrollan y refuerzan el sexismo y el odio hacia las mujeres en los consumidores de pornografía? En primer lugar, cualquier intervención feminista contra la pornografía debe encontrar un modo de singularizarla y distinguirla de aquello que se considera como simplemente erótico. $\mathrm{Si}$, al menos momentáneamente, aceptamos junto a Thornton que por erótico podemos entender a toda representación sexualmente explícita que expone a los seres humanos de modo tal que preserva su dignidad humana, entonces podemos preguntarnos: ¿es posible tener una pornografía aceptable, es decir representaciones liberadas de material moralmente objetable que sigan siendo una fuente de placer sexual, incluso de excitación sexual?

Desde otra perspectiva, Cassandra Amesley (1988) analiza el modo en que la definición de sexo de las feministas radicales multiplica en extremo las zonas de peligro potencial para las mujeres. En su análisis interrelaciona lo erótico, lo obsceno y lo pornográfico sin ignorar el bagaje ideológico de cada uno de estos términos. Amesley asume, como punto de partida, que en el campo representacional de la sexualidad existe un espacio que diferencia las representaciones deseables de las representaciones indeseables.

Si Thornton opone en su análisis lo erótico a lo pornográfico, Amesley sitúa en los extremos del espectro lo obsceno por un lado, y lo erótico por otro. En sus intentos de cercar el significado retórico de lo obsceno concluye que, a diferencia del modo en que el 
término parece estar instaurado socialmente, no se corresponde de manera absoluta con la capacidad de generar sentimientos asquerosos $\mathrm{u}$ ofensivos. Lo obsceno refiere a un lugar de una extensa red en donde ciertos grupos con intereses diferentes compiten por abrirse paso y aplicar dicho término al material que ellos desean borrar del discurso público. En este sentido, en palabras de Amesley, "el término obscenidad lleva consigo los códigos de poder y control y la capacidad coactiva de hacer cumplir la definición de un término. Por lo tanto, el debate alrededor de la pornografía qua obscenidad es un debate que concierne la intervención en las prácticas discursivas de sexo" (Amesley, 1988, 92). En esta trama, la autora sitúa la pornografía como término medio entre lo erótico y lo obsceno, así se distancia de las feministas radicales, para quienes la pornografía es en sí misma indeseable, lo que conduce a rechazar el término de entrada. Es decir, si se trueca lo pornográfico por lo obsceno, y aceptamos el cambio terminológico, lo pornográfico queda liberado del rechazo inicial, por lo que surge la posibilidad de ponerlo a consideración, otorgarle nuevos significados y comprenderlo en su sentido retórico. En consecuencia, el intento de agregar un término más trastoca el esquema que divide la sexualidad humana en dos polos, en cuyos extremos se ubican las mujeres, por un lado, y los varones por otro, y que identifica a los varones con lo pornográfico y a las mujeres con lo erótico. Por un lado permite un primer deslizamiento hacia una desnaturalización posible, por otra parte abre la posibilidad de considerar, tal como lo formula Feona Attwood (2002), el contexto semiótico de las representaciones sexuales a fin de ubicar los materiales pornográficos en relación a las cuestiones de género, estilo, sensibilidad, dirección y forma.

Cuestiones del contexto geográficos y sociales, la ubicación y el acceso, la situación, el poder y las características de los grupos de consumidores, son cruciales para establecer no sólo qué tipos de representaciones están disponibles para el consumo, y a quienes se refieren, sino dentro de qué tipo de relaciones esta configuración se lleva a cabo y cómo impacta en la experiencia de los consumidores. También, el contexto histórico y cultural de los materiales necesita ser investigado ya que constituye un modo de establecer la forma en que éstos están culturalmente marcados como pornográficos o no pornográficos, como materiales restringidos o no restringidos, como representaciones de 
bajo, alto o mediano gusto, como peligrosos o seguros, opresivos o transgresores. La audiencia de lectura de material sexualmente explícito, y la colocación y el uso de este material en relación con la construcción de identidad de género, conocimiento, placer y comportamiento sexual se encuentra, a criterio de Atwood, influenciados por todos estos factores contextuales.

\section{Realidad y fantasía: algunas diferenciaciones, varios riesgos}

Como hemos visto, algunas feministas radicales asumen que la conexión entre la pornografía y la violencia sexual es absolutamente obvia, pero, como indica Neil Thornton, falta evidencia en las investigaciones realizadas hasta el momento que develen el eslabón causal entre la pornografía y la violencia sexual. Algunas situaciones de laboratorio, en el marco de estudios conductistas, se han montado con el esfuerzo de establecer los efectos de la pornografía. Los resultados son favorables respecto a la tesis que sostiene que la pornografía causa directamente actos particulares de violencia contra las mujeres. De todas formas, es indudable lo inapropiado que resulta extrapolar una situación experimental por fuera del laboratorio del experimentador. En estas situaciones artificiales no se observa el verdadero comportamiento violento, sino un sustituto que involucra objetos representativos en una situación fingida (para ejemplos de varias investigaciones en relación al tema véase Williams et al., 2009; Carrol et al., 2008; Hinson Shope, 2004; Norris et al., 1999). En consonancia, las feministas liberales afirman que los datos provenientes de las investigaciones de las ciencias sociales no apoyan las amplias generalizaciones realizadas por las feministas radicales en su ancias de denunciar la pornografía. Aunque algunas feministas radicales citan estos datos para sustentar sus afirmaciones, las feministas liberales sostienen que es evidente la selección de los datos utilizados, por lo que hay una clara distorsión en la utilización de las múltiples investigaciones sobre los efectos de imágenes sexualmente explícitas.

La psicología conductista no es un basamento lo suficientemente sólido para demostrar una conexión causal entre el consumo de pornografía y la violencia sexual contra las mujeres. 
El punto flaco que torna vulnerable tales pretensiones parece estar en la distinción crucial entre la fantasía sexual y el mundo de acción humana.

Si suponemos que la violencia de los varones es un eslabón causal inmediatamente posterior al empleo de pornografía, en donde el comportamiento se ve obligado a poner en marcha lo representado en la pornografía, delimitamos un modelo de ser humano gobernado por estímulos y respuestas en donde la fantasía avanza y coloniza la motilidad misma. Siguiendo estas coordenadas, abordar la pornografía como la violencia contra las mujeres, o como la mascarada de un comportamiento sexista, implicaría confundir fantasía y realidad, ya que "la pornografía no es una representación en palabras o cuadros de un mundo de verdaderas personas y acontecimientos, sino la representación de un mundo de ficción" (Thornton, 1986, 36). También para Jessica Benjamin, los conflictos que suscitan los debates sobre la pornografía refieren, en última instancia, a la disyunción entre fantasía y realidad. La autora se muestra en contra de considerar que los contenidos de la pornografía develen la verdad oculta en la realidad, específicamente la dominación y destrucción inherente a la excitación sexual de los varones, tal como lo afirma Dworkin.

Equiparar lo que expresa la pornografía a lo que todos los varones requieren en su vida sexual no parece ser conveniente a los fines de conseguir argumentos sólidos. Por otra parte, tal como señala Benjamin, estas afirmaciones dan por sentado que los deseos del ser humano son sencillamente lo que parecen, por lo que desarticulan la compleja trama que el psicoanálisis ha tejido entre deseo, sexualidad y fantasía. El excesivo acento en la dimensión de la fantasía ha llevado a algunos psicoanalistas a buscar la verdad del sujeto en las formaciones inconcientes que emergen como producto del levantamiento de la represión. Por el contrario, algunas feministas han colocado en primer plano el significado traumático de los acontecimientos reales. Confundir estos planos implica equiparar las representaciones de la fantasía con la realidad, por tanto no distinguir entre lo concreto y lo simbólico. Los movimientos de antipornografía, en general, a criterio de Benjamin, incurren en este error y atribuyen a las imágenes pornográficas la misma eficacia traumática que los hechos reales. La argumentación, entonces, se plantea en términos de efectos reales. En palabras de la autora: 
La violencia real no puede limitarse a la relación especular con la excitación sexual ni ser contenida por ella; excede la representación. La Pornografía, con algunas excepciones, nos limita a la imagen, la escenificación, la hazaña simulada. (...) Clausura el espacio entre el símbolo y el objeto, y hace que el objeto representado parezca ser 'la cosa' que provoca excitación, pero la cosa es precisamente no real (Benjamin, 1997, 224).

Ahora bien, las líneas argumentativas de Neil Thornton y Jessica Benjamin parecen, aunque más no sea por momentos, ir demasiado lejos. Pensar las representaciones que se despliegan en los materiales pornográficos como un mundo desprovisto de realismo no se transforma en un alivio para la violencia entretejida en la realidad de muchas mujeres, muy bien documentada (Kitzinger et al., 1992).

Thornton parece advertir estos desvíos y aclara que indudablemente fantasías pornográficas y conducta sexual se conectan y articulan de algún modo. Sea como fuere, cualquiera que sea la conexión no puede ser tan directa y sencilla como el modelo conductista nos haría creer. Este modelo de condicionamiento no tiene lugar para incluir la complejidad que supone incorporar la categoría de fantasía en los escenarios de la sexualidad y de la pornografía. Algunos esfuerzos pueden haberse vistos perjudicados al buscar respuestas y aliados en teorías pobres. Como resultado, algunos análisis de feministas radicales de la pornografía simplifican demasiado la conexión entre la fantasía sexual y el comportamiento. Por un lado reducen la sexualidad humana al acto sexual (genital), por otro lado, ubican la dimensión de la fantasía con el poder de influenciar directamente sobre el comportamiento.

En tal sentido, sostener que la pornografía ejerce una influencia directa sobre la constitución del carácter sexual masculino, no sólo implica afirmar la existencia de un carácter sexual masculino específico, también supone que la identidad sexual del ser humano se encuentra completamente determinada por los discursos sociales. Por ejemplo, MacKinnon da por sentado que la psicología de los géneros opera a través de la definición social de los varones y las mujeres (Benjamin, 1997). Muchas feministas suponen que la pornografía es capaz de moldear la vida de las personas, esto explica que no duden en afirmar que las construcciones sexistas de las mujeres al interior de la pornografía se transfieren a la conducta interpersonal. 
Según Esther Reed (1994), la pregunta no es acerca de las imágenes per se, sino acerca de cómo son percibidas. Una representación de actividades se convierte en pornográfica debido a las formas convencionales en que las representaciones son vistas. Elizabeth Wilson menciona que la imaginación es 'pornográfica', no la imagen (Wilson, Cit. en Reed, 1994). La pregunta no es de contenido sino de forma, producción y consumo. Reed intenta deshacer todo el concepto mismo de pornografía al negarse a definir el material sexualmente explícito a través de los rasgos diferenciales con otros materiales, sino, más bien, a partir de los reinos de la representación.

Reed afirma que la fuerza del llamado enfoque post-moderno permite, en primer lugar, establecer las reglas sociales como centro de atención. En segundo lugar, rechaza la homogeneización de la cultura occidental como monolíticamente patriarcal en su uso de imágenes pornográficas. Por otra parte, si es cierto que el material es pornográfico sólo en términos de la forma en que se usa, podemos suponer que toda la pornografía es ilusoriamente creada de manera independiente a los hechos que se despliegan efectivamente en el mundo real. Tal posicionamiento transforma problemáticas centrales -la explotación sexual, la comercialización y la trata de seres humanos, o las normas que regulan la explotación sexual- en completamente irrelevantes al interior de los términos del debate sobre la pornografía.

\section{A modo de cierre}

No se debe perder de vista que la pornografía se integra en procesos sexistas más generales, en un malestar cultural mucho más amplio y profundo. La pornografía reproduce, despliega y propaga significaciones que constituyen una expresión directa que recapitula la estructura del patriarcado de un modo crudo y desenmascarado, a modo de un monumento recordatorio de la subordinación de las mujeres que se alza en medio de nuevos sexismos, sutiles y sofisticados, que entretejen una igualdad ilusoria entre los sexos.

Las feministas radicales se han centrado en la pornografía como una fuente principal de sexismo, como la manifestación ideológica principal de la dominación sexual patriarcal. 
Al realizar un análisis desde un punto de vista unitario (Segal, 1998), es posible pensar que las feministas radicales tomaron a la pornografía como representante metonímica de la totalidad del patriarcado. Mientras los ataques van dirigidos hacia aquel blanco claramente localizado, el sexismo, naturalizado, sigue filtrándose de manera masiva, y sutilmente cifrado, a través de los medios de comunicación y el mundo de la publicidad.

Por otra parte, es evidente que la posibilidad de modificar el sexismo y la violencia contra las mujeres requiere, necesariamente, de un cambio en la masculinidad hegemónica y normativa. Esencializar la identidad de género masculina, como modo de luchar contra la pornografía y el patriarcado, es una estrategia que se vuelve en contra de tal objetivo. Los varones debemos desnaturalizar nuestras identidades y lanzarnos en la búsqueda de masculinidades alternativas más justas y equitativas.

Mi propia experiencia como varón que ha crecido en una sociedad altamente machista me indica que es posible escapar a las significaciones instituyentes de masculinidades dominantes, sexistas y violentas. Reflexionar sobre las coordenadas políticas que subyacen a nuestras identidades de género implica reconocernos a nosotros mismos como pilares concretos y cotidianos del patriarcado. Los patrones que se encuentran a la base de la masculinidad hegemónica generan una plataforma identitaria que otorga reconocimiento e inteligibilidad social a quienes degradan a las mujeres, social y sexualmente. La vinculación existente entre el reconocimiento alcanzado por la reproducción de los patrones normativos que integran la homosocialidad masculina -léase pactos patriarcales entre varones- y la violencia sexual contra las mujeres ya ha sido convincentemente demostrada (Michael Flood, 2008). Si, tal como afirma Nancy Chodorow (1984), la identidad de género masculina se constituye de manera reactiva ante lo femenino rechazado, entonces el repudio continuo hacia las mujeres no sólo posibilita a los varones la obtención de reconocimiento por otros miembros del grupo sino, también, la autoafirmación del propio sentido de mismidad. De modo que la transición hacia masculinidades alternativas supone una fuerte crisis identitaria ya que, al menos en parte, supone dejar de ser quienes somos.

Sea como fuere, es posible escapar de las garras del patriarcado y desembarazarnos del potente anclaje que la socialización 
de los roles de género ha interiorizado en nuestras identidades. El sujeto es capaz de reelaborar las normas y cuestionar los mandatos de género. Cuando esto ocurre, múltiples dispositivos de violencia se activan como mecanismos de disciplinamiento que pretenden mantener la coherencia del sistema sexo / género en un equilibrio homeostático. Yo mismo he sido, y soy, víctima de la violencia intragénero -ejercida entre varones- desplegada cuando algo disruptivo se presenta, obstaculizando el correcto funcionamiento de los engranajes que ponen en marcha al patriarcado. Yo mismo encarno el fracaso de la masculinidad hegemónica, plausible de ser modificada. Yo mismo encarno la posibilidad de instaurar una discontinuidad en la exigencia de repetición constante de las normas de género (Butler, 2004), las cuales garantizan la estabilidad del patriarcado.

Para luchar contra la pornografía es necesario, en primera instancia, desarticular las estrategias de naturalización que otorgan a la superficie del patriarcado una apariencia compacta. Para ello, es necesario atacar desde varios frentes. La participación de los varones en este proyecto constituye una exigencia ética.

En el contexto de un mundo en que los géneros se constituyen bajo la apariencia de significados unívocos y esencialmente inalterables, y claramente sirven al cumplimiento de una política patriarcal de regulación y control social/sexual, el género es asumido bajo coacción a diario. Alejarnos del esencialismo y comenzar a decodificar los mandatos de género como datos que responden a estrategias de poder permite, a mujeres y a varones, emprender la búsqueda de nuevas figuras de lo erótico que escapen a las capturas pornográficas de las formas patriarcales de sexualidad.

\section{Notas}

1 Académico del Instituto de Investigaciones en Humanidades y Ciencias Sociales (IdIHCS) del Centro Intedisciplinario de Investigaciones en Género (CINIG), Universidad Nacional de La Plata.

2 Una primera sistematización sobre este punto fue realizada en: -Martínez, Ariel. "Sexualidad, violencia e identidad de género en los debates sobre la pornografía. Algunas consideraciones desde la complejidad de su aborda$\mathrm{je}^{\prime \prime}$. Actas de I Congreso Interdisciplinario de Género y Sociedad. Facultad 
de Filosofía y Humanidades, Universidad Nacional de Córdoba, Argentina, 2009. Al mismo tiempo, es absolutamente deudor de las elaboraciones realizadas por Neil Thornton y Barbara Collins.

\section{Bibliografía}

Amesley, Cassandra. "Marginal Sexual Practices: Pornography, Feminism and the Struggle with the State". Journal of Communication Inquiry. 12 (1988): 90-103.

Attwood, Feona. "Reading Porn: The Paradigm Shift in Pornography Research". Sexualities. 5/1 (2002): 91-105.

Aulagnier, Piera. La violencia de la interpretación, Buenos Aires: Amorrortu, 2004.

Badinter, Élisabeth. Hombres/Mujeres. Cómo salir del camino equivocado. Buenos Aires: Fondo de Cultura Económica, 2003.

Benjamin, Jessica. Los lazos de amor. Psicoanálisis, feminismo y el problema de la dominación. Buenos Aires: Paidós, 1996.

------. Sujetos iguales, objetos de amor. Ensayos sobre el reconocimiento y la diferencia sexual. Buenos Aires: Paidós, 1997.

Braidotti, Rosi. Sujetos nómades. Buenos Aires: Paidós, 2004.

Butler, Judith. El género en disputa. El feminismo y la subversión de la identidad. Barcelona: Paidós, 1990.

------. Undoing Gender. New York: Routledge, 2004.

Carrol, Jason et al. "Generation XXX. Pornography Acceptance and Use Among Emerging Adults". Journal of Adolescent Research. 23/1 (2008): 6-30.

Chodorow, Nancy. El Ejercicio de la Maternidad. Barcelona: Gedisa, 1984.

------. El poder de los sentimientos. La significación personal en el psicoanálisis, el género y la cultura. Buenos Aires: Paidós, 2003.

Ciclitira, Karen. "Pornography, Women and Feminism: Between Pleasure and Politics". Sexualities. $7 / 3$ (2004): 281-301.

Collins, Barbara. "Pornography and Social Policy: Three Feminist Approaches". Affilia. 5/ 4 (1990): 8-26.

Dinshaw, Carolyn. "Perspectivas Queer". Carabí, Àngels \& Josep Armengol, comp. La masculinidad a debate. Barcelona: Icaria, 2008.

Dio Bleichmar, Emilce. "Del sexo al género". Revista Asociación Escuela Argentina de Psicoterapia para Graduados. 18 (1992): 127-155.

Dorlin, Elsa. Sexo, género y sexualidades. Introducción a la teoría feminista. Buenos Aires: Nueva Visión, 2009.

Dworkin, Andrea. Pornography: Men Possessing Women. London: The Women's Press, 1981.

Femenías, María Luisa. "Identidades esencializadas / violencias activadas". ISEGORÍA Revista de Filosofía Moral y Política. 38 (2008): 15-38.

Flood, Michael. "Men, Sex, and Homosociality: How Bonds between Men Shape Their Sexual Relations with Women". Men and Masculinities. 10/3 (2008): 339-359.

Fraser, Nancy y Linda Nicholson. "Crítica social sin filosofía: un encuentro entre el feminismo y el posmodernismo". Nicholson, Linda, comp. Feminismo / Pormosdernismo. Buenos Aires: Feminaria, 1992. 
Gergen, Mary. “Undbundling Our Binaries - Genders, Sexualities, Desires”. Feminism \& Psychology. 2 (1992): 447-450.

Hinson Shope, Janet. "When Words Are Not Enough: The Search for the Effect of Pornography on Abused Women". Violence Against Women. 10/1 (2004): 56-72.

Jensen, Robert. "Knowing Pornography". Violence Against Women. 2 / 1 (1996): 82-102.

-----. Getting Off: Pornography and the end of Masculinity. Cambridge: South End Press, 2007.

Kitzinger Celia et al. "Theorizing Heterosexuality". Feminism \& Psychology. 2 (1992): 293-324.

Lamas, Marta. "La antropología feminista y la categoría de 'género"”. Nueva antropología. VIII/30 (1986): 173-198.

Mayobre Rodríguez, Purificación. "La formación de la Identidad de Género. Una mirada desde la filosofía”. Esteve Zarazaga, José Manuel y Julio Vera Vila, comp. Educación Social e Igualdad de Género. Málaga: Ayuntamiento de Málaga, 2006.

Millet, Kate. Política sexual, Madrid: Cátedra, 1995.

Norris, Jeanette et al. "Alcohol and Hypermasculinity as Determinants of Men's Empathic Responses to Violent Pornography". Journal of Interpersonal Violence. 14/ 7 (1999): 683-700.

Osborne, Raquel. La construcción sexual de la realidad. Un debate en la sociología contemporánea de la mujer. Madrid: Cátedra, 1993.

Reed, Esther. "Pornography and the End of Morality?". Studies in Christian Ethics, 7 (1994): 65-93.

Reinharz, Shulamit. "How My Heterosexuality Contributes to My Feminism and Vice Versa". Feminism \& Psychology. 2 (1992): 450-453.

Segal, Lynne. "Only the Literal: The Contradictions of Anti-pornography Feminism". Sexualities, 1/1 (1998): 43-62.

Stoller, Robert. Sex and Gender. New York: Science House, 1968.

Thompson, Denise. "Against the Dividing of Woman: Lesbian feminism and Heterosexuality". Feminism and Psychology. 2/3 (1992): 387-398.

Thornton Neil. "The Politics of Pornography: A Critique of Liberalism and Radical Feminism". Journal of Sociology. 22/1 (1986): 25-45.

Williams, Kevin et al. "Inferring Sexually Deviant Behavior From Corresponding Fantasies: The Role of Personality and Pornography Consumption". Criminal Justice and Behavior. 36/2 (2009): 199-222.

Young, Alison. "The Authority of the Name". Feminism \& Psychology. 2 (1992): 422-424. 